\title{
¿HABRÁ QUE CANTAR EN LOS TIEMPOS DIFÍCILES?*
}

Por: Marthe Senn'

$\mathbb{N}$

o es ususi para mi la expresión a través de un discurso. Lo que yo sé hacer es cantar y más de la mitad de mi vida la he pasado interpretando melodias con las que espero haber comunicado y sobre todo, emocionado. Por eso le agradezco al Señor Rector Cesar Vallejo que me permita expresar en esta ocasión unas palabras con las que aspiro reflejar la coincidencia de mis apreciaciones con la misión de este centro universitario.

Ante los horrores del mundo y de Colombia me pregunto a la manera de Bertolt Brecht : ¿Habrá que cantar en los tiempos dificiles? Y me respondo que si por razones de mi actividad artística, dijera que lo mío no es el interés por el acontecer nacional, no sólo le estaria volteando la espalda a Colombia, sino desconociendo mis más profundos sentimientos.

Y es precisamente desde la Universidad, ese espacio donde concurren el rigor, la disciplina y la creatividad en las distintas áreas del conocimiento, desde donde se tienen que gestar propuestas que soporten las grandes reformas politicas y sociales que Colombia necesita y que tan sólo tendrán lugar el dia en que logremos frenar la desbocada carrera de la insensatez. impulsada por intereses voraces, para darle paso al conocimiento y a la conveniencia social.

A ustedes, futuros profesionales comprometidos con la visión de este centro de educación superior, les toc $\delta$ la mala fortuna de heredar un pais donde desde distintos escenarios se producen daños inconmensurables. Fijémonos: ¿Quiénes circulan por los escenarios politicos? Con palabras llenas de promesas, parecen sin embargo haber olvidado que la politica es un arte, que asi se ha definido desde siempre y que tal vez sea el arte más trascendental para una colectividad.

Son muy escasas las voces que desde estos escenarios comprenden que el aima de la politica está tanto en su contenido como su continente que son la ética y la estética.
- Discarso pronundado an la ceremonia de grades de ta UAM el 26 de marzo de 2003

"La mezzosoprato, Martho Senn, gulen brilla por su vor Y habildad dramátice, ha sido aplauelida en tres contitnentes. Es una mujer inteligente que ha sabido aprovechar cada una de fas oportunidades que if ha dedo to vida. Eila, quer estucio en ef conservatario de la Unversidad Wociocial de Calombia, plano. armonia, teoria, soteo e historia de ta mústica y Derecho en la Univeridad del Rasario, se decibió por el arte, que it ha aboerto las puertas de los principaies escenarios del mundo, entre clios: El Festival de Saizbungo, la Bastilla, de Parts, ia Fenice $y$ el Conservatorie de Milan.

En diciembre de 1984, inivitada por el maestre Claudio Abbado, debutó en ia Scala de Mison, el teatro de Verdi, de Rassini $y$ de Puchin, interpretando ef papes de "Rosina' en la abra Ei Barberu de Sevilla $y$. des p u és. tu vo presentaciones descritas como "excepcionales". pespucs do ganar el Cancurso Intemecional de Canto en Paris en 1982, las contracadones para Martha Sennse ha mutiplcedo :

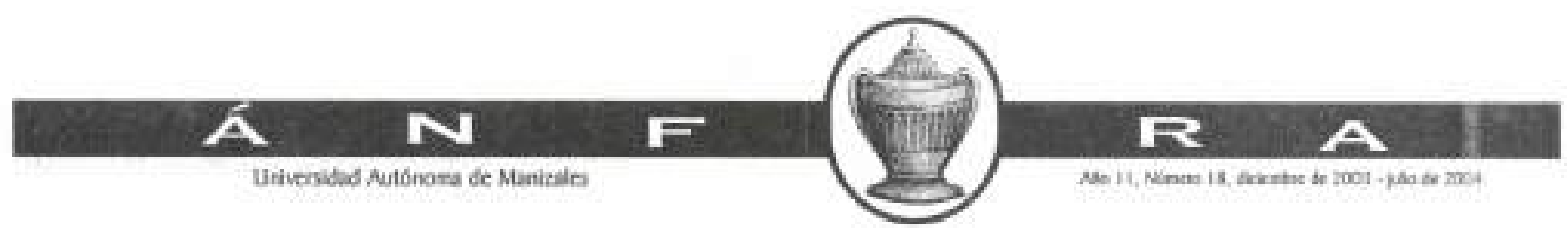


En otras palabras, que no basta con que la politica sea buena, sino que debe ser también belia para que como todo arte, comunique, y construya lo que tanta falta nos está haciendo: una cultura politica válida para la sociedad.

A los actores politicos, tenemos el derecho ciudadano de exigirles que traduzcan a la realidad las nociones esenciales de la democracia, que llenen de verdad la definición más elemental: iEl gobierno del pueblo por el puebloy para el puebloi de la que nos habló Lincoln.

Tenemos el derecho ciudadano a que nos rescaten de la tristeza con la que el Maestro Dario Echandia se nos fue, tildando la democracia colombiana como el gobierno de los ignorantes por los ignorantes y para los ignorantes.

Y más allá de esto, tenemos además tanto el derecho ciudadano como la responsabilidad de borrar del imaginario colectivo nacional e internacional, la idea de que Colombia es una democracia de corruptos por corruptos y para corruptos. $Y$ esa si es una tarea que nos corresponde a todos, a ellos, los que están en el escenario de la politica, y a nosotros, quienes que los estamos mirando.

Lideres politicos que no se apoyen en los principios esenciales de la estructura democrática como lo son la existencia de instituciones fortalecidas que garantizan el Estado de Derecho y partidos politicos firmes, irrigados por ideologias sostenibles en el horizonte de la seriedad y el compromiso, son simplemente jefes efimeros.

Son además peligrosos porque bien saben que si llegan al poder, carecerian de gobernabilidad, y a base de populismo estarian atrayendo el caos social. $Y$ Colombia no necesita, con este tipo de malsanos liderazgos, verse repetida en las experiencias de algunos vecinos latinoamericanos.

De modo que nuestra actitud ciudadana tiene que ser responsable convencida y convincente. No nos podemos conformar tan solo con dejar al pais en manos de políticos bien intencionados. Al fin y al cabo, todos parecen serlo. Tenemos la obligación de dejar a Colombia en las mejores manos.

Pero entre las bambalinas de este escenario politico que estoy describiendo, se han quedado otras voces que queremos escuchar y ver portando la linterna cartesiana con la que lluminen el qué, el por qué y el para qué de esta Colombia que se siente perdida y que no parece estar haciendo camino al andar como lo canta el poeta.

Dónde están los filósofos politicos de este pais?... Son escasos .

La Academia está en mora de tomar por las riendas el poder que le es natural, ejercerlo y aparecer desde la Universidad como otro protagonista.

- en la Arena de Verona, Martha Sern obtuvo uno de sus mis grandes exitos. Iguaimente en la Opera de la Bastilla, a la que regreé en marzo de 1994, para interpretar "Carmen" de Bzet, con rotundo exita. Para eilo ensayó durante 15 dias, entre 10 y 12 horas diarlas, solo en la parte escinica. En lo musical ya estaba prepareda." (Nota to m a d a de www.embcolfrancia.com/2s panish/3colombia/4cultura/ Ssenn(senn-hom)

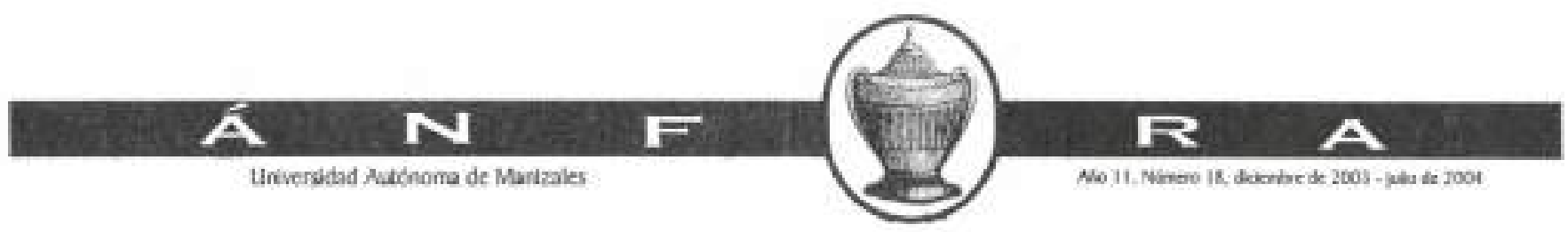


Gobernantes y gobernados necesitamos que desde alli se empiece a generar conciencia ciudadana.

Me rehuso a pensar que nos debamos mantener condenados a ocasionales análisis criticos de fondo a los que poca resonancia dan los medios de comunicación.

Nuestros jóvenes se han ido deformando frente a la idea de lo politico. A nuestros niños y niగ̄as se los educa sin estimulo a los talentos que les son propios y sin una clara conciencia ciudadana, Están creciendo con referencias psicológicas y emotivas de repugnancia hacia todo lo que signifique politica.

Grande es la responsabilidad educativa en ese sentido, pero sobretodo la de los medios de comunicación en la manera de presentar y proyectar un tema que afecta y determina la vida cotidiana y el destino de nuestra democracia.

Pero desafortunadamente, desde el foso de este escenario de la vida politica colombiana, la comunidad internacional y el pais entero, no escuchan otro acompañamiento que el de lamentos, quejas, gritos, causados por el horror de balas, bombas, quiebra patas.

Esta orquesta infernal interpreta la más desgraciada de las partituras con la que hace presencia la alevosia armada. Un porcentaje minimo de los habitantes de este pais ha preferido escoger como rutas de su destino, no los caminos de la vida, sino los caminos de la muerte. Llevan afios escudándose en la lamentable realidad de nuestra injusticia social, para comportarse como colombianos que matan colombianos y como colombianos que se matan entresi.

Los ciudadanos y ciudadanas nos negamos a aceptarlos en su pretensión de ser los representantes del pueblo. A nosotros no nos representan sino quienes elegimos por las vias democráticas. Si quieren serlo, deben a éstas someterse.

A ellos, a los alzados en armas les reclamamos como minimo, el derecho a llorar a nuestros muertos, a llevarnos en la memoria el duelo por tanta sangre inútimente desperdiciada.

Y a quienes creen encontrar en la abierta y total confrontación guerrera principios de solución a nuestra conflictividad, les reciamamos, nuestro legitimo derecho a sentirle miedo a la guerra . $Y$ aunque comprendemos que a los aizados en armas los territorios del sosiego le sean desconocidos y por lo tanto generadores de incertidumbre, les decimos con la más sonora de nuestras voces para que puedan oimos bien, que ellos por el contrario, no

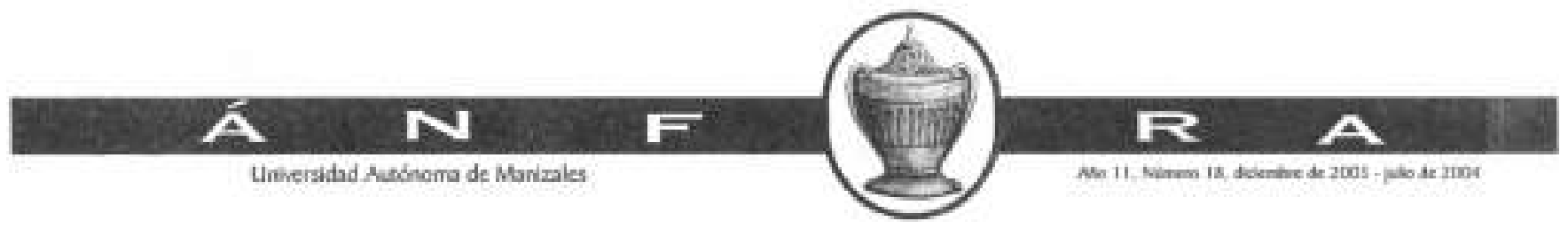


tienen nitngùn derecho a sentirle miedo a la paz, Que "al temor hay que mirario directamente a los ojos para que se asuste y se vaya" como lo propone Kazanzakis,

A quienes intentan dominar con el imprevisible lenguaje del terror, hay que saberlos conducir a que reconozcan la existencia de generosos mecanismos que ofrece el sistema democrático como son: la construcción de los consensos y disensos y la sana oposición, con los cuales se hace posible escuchar todas las voces de una sociedad.

Como ciudadanos, debemos estar listos y dispuestos a retar a los violentos a que se bajen de los hombros el fusil para que se preparen con otro tipo de armas, las carguen con la dinamita de la originalidad y nos disparen ideas, con tan certera punteria, que logren conmover el denominador común de todos los colombianos: la inteligencia.

Es ahi en ese campo de batalla, el de la inteligenda, en donde nos queremos ver y confrontar con quienes practican como credo el de la dominación armada, porque en ese territorio no hay vencidos. Tan solo vencedores, $y$ en esa calidad, la de vencedores, podremos por fin diseñar un escenario donde se pueda reinventar el perdón, ya que tan sólo a partir de alli nos será dado rescatarnos de las arenas movedizas de la sed de venganza y la intolerancia, y erguimos orgullosos sobre los cimientos de la justicia, el trabajo y la educación.

Pero en alguna parte hemos fallado los colombianos y las colombianas todos. Porque sobre la inmensa riqueza geográfica de nuestro pais donde reposa su formidable diversidad humana, y cultural, no hemos hallado todavia, tal vez por las condiciones dramáticas del diario vivir, otro tipo de escenarios: Aquellos que nos permitan conocernos.

Esta magnifica diversidad humana que es nuestra fortaleza, es también nuestra desgracia porque Colombia no ha encontrado aún como verificarse, intercambiarse, transformarse e incrementarse en su riqueza como nación.

Sin cultura ni educación es imposible que un proceso de paz y de recuperación de los valores de convivencia se abra un camino sostenible. Tanto más en Colombia donde los conflictos nacen del desencuentro y se reproducen por la incapacidad de tantos sectores para comunicar su idea de pais.

Hay entonces que darle una dimensión cultural a la solución de la guerra. Este es el escenario que tenemos que abrir.

Tarea dificil? ...si Imposible? ... no, si se piensa que Colombia es un pais creativo por excelencia donde basta ofrecer una oportunidad para que se

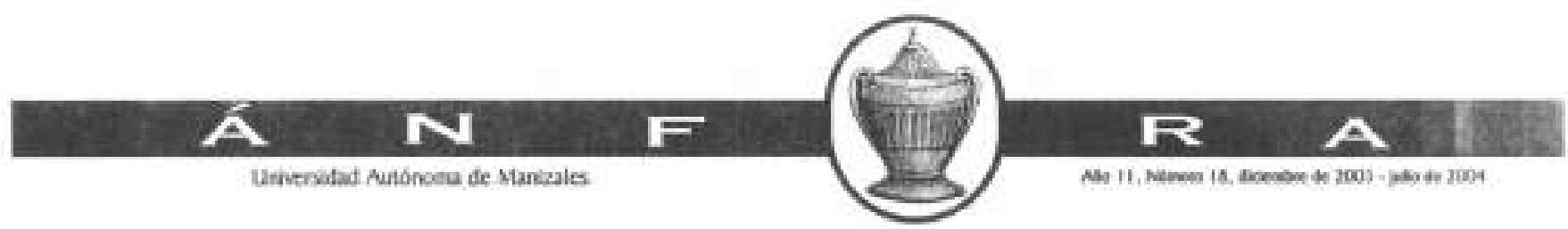


aglomeren personas de todas las edades, condiciones sociales y económicas, listas a proponer, a apreciar lo creado, a investigar, a imaginar soluciones y respuestas.

Somos los artistas por naturaleza poseedores de una gran capacidad expresiva pues bien, no podemos hacer menos que poneria al servicio de la Nación para identificar lo que nos une y tambièn lo que nos hace distintos unos a los otro5, para confrontarnos no en la discordia sino en la afirmación, no en el rechazo sino en la aproximación.

Por intermedio del arte podemos buscarnos, encontrarnos y reconocernos con originalidad, no sólo para mostrarnos ante el mundo y decir quiénes y cómo somos, sino también para mirarnos a nosotros mismos, aprender a dialogar, y aprendernos a querer que es una de las carencias que más problemas nos genera, sino todos.

La cultura debe ser un factor de consideración tan importante que se coloque dentro de los procesos de pacificación en el mismo nivel de presencia con lo politico y to militar. No me refiero tan solo a to puntual de la cultura espectáculo desde cuyos escenarios me he movido como artista, sino a la imperiosa necesidad de abrir procesos culturales sostenibles a mediano y largo plazo.

No cabe la menor duda. Los únicos espacios de convergencia en donde se neutralizan las polarizaciones, son los lenguajes creativos.

Estas reflexiones deben ser válidas no sólo para la comprensión y superación de nuestras dificultades internas, sino para la consolidación de unas mejores relaciones internacionales.

Entonces, con esta voz a la que desearia se le unieran las voces de todos y todas las colombianas que estamos pensando en el pais y en $5 u 5$ crecientes dificultades, quiero hacer una invitación consistente en convertir a Colombia en un laboratorio de solución de conflictos por la via de fa cuitura y darle así al resto del conflictivo mundo, un gran ejemplo.

Por último quiero hacerles escuchar otra voz, la del poeta Enrique Buenaventura cuando responde asi at interrogante brechtiano ¿Habrá que cantar en los tiempos dificiles?

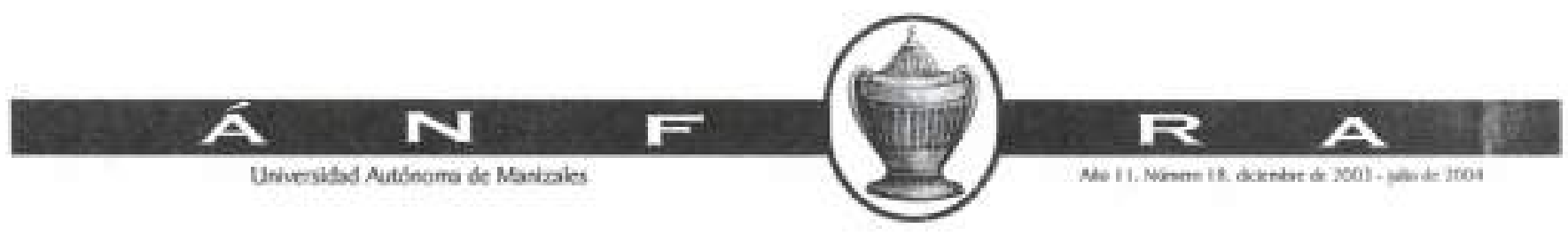


qu gente sucfe decir

no es este tiempo un tiempo para cantar.

Es un tiempo maldito, un tiempo para caflar.

$\Upsilon$ yo digo ihay que cantar!

Hay que cantar ahora,

en este ninuto, en esta pofvareda de segundos,

hoy aqui, en este cementerio

iqhay que cantar!

Hay que cantar para hacer safir ef sol,

para que se abran las flores,

para que engendire ta tierra,

para que sientan los hombres que la sangre por las arterias

sube a sus corazones.

Sólo la voe derrota al grito,

apaga af alarido $y$ seca ef flanto.

$Y$ detiene af asesino

y apfaca fa fos focos $y$ a las fieras.

Tay que cantar ahora,

en este sitio en donde estamos sitiados

por la violencia $₹$ la guerra.

M(uchas gracias

Sanizales, 9arzo 26/03

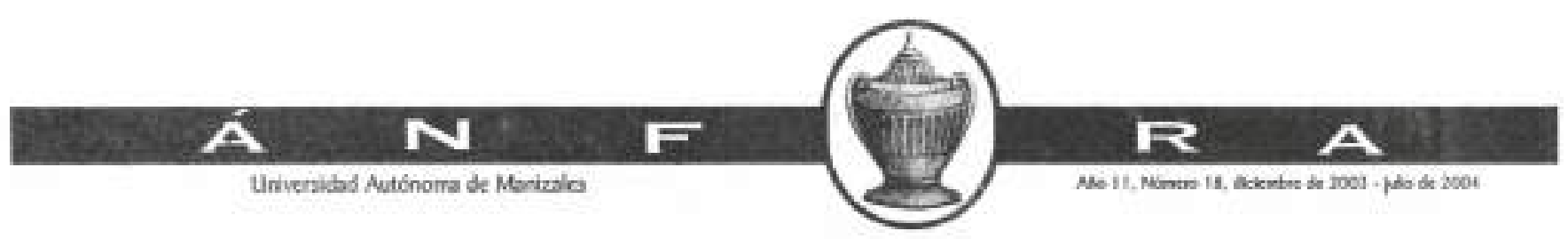

